\title{
Effects of Pre- and Postanthesis Applications of Demethylation Inhibitor Fungicides on Fusarium Head Blight and Deoxynivalenol in Spring and Winter Wheat
}

Pierce A. Paul, ${ }^{\dagger}$ Department of Plant Pathology, The Ohio State University, Ohio Agricultural Research and Development Center, Wooster, 44691; Carl A. Bradley, Department of Plant Pathology, University of Kentucky Research and Education Center, Princeton, 42445; Laurence V. Madden and Felipe Dalla Lana, Department of Plant Pathology, The Ohio State University, Ohio Agricultural Research and Development Center, Wooster, 44691; Gary C. Bergstrom, Plant Pathology and Plant-Microbe Biology Section, School of Integrative Plant Science, Cornell University, Ithaca, NY 14853; Ruth Dill-Macky, Department of Plant Pathology, University of Minnesota, Saint Paul 55108; Kiersten A. Wise, Department of Botany and Plant Pathology, Purdue University, West Lafayette, IN 47907; Paul D. Esker, Department of Plant Pathology and Environmental Microbiology, Pennsylvania State University, University Park, 16802; Marcia McMullen, North Dakota State University, Department of Plant Pathology, Fargo, 58108; Arvydas Grybauskas, Department of Plant Science and Landscape Architecture, University of Maryland, College Park, 20742; William W. Kirk, Department of Plant, Soil and Microbial Sciences, Michigan State University, East Lansing, 48824; Eugene Milus, Department of Plant Pathology, University of Arkansas, Fayetteville, 72701; and Kay Ruden, Plant Science Department, South Dakota State University, Brookings, 57007

\begin{abstract}
Anthesis is generally recommended as the optimum growth stage for applying a foliar fungicide to manage Fusarium head blight (FHB) and the Fusarium-associated toxin deoxynivalenol (DON) in wheat. However, because it is not always possible to treat fields at anthesis, studies were conducted to evaluate pre- and postanthesis treatment options for managing FHB and DON in spring and winter wheat. Network meta-analytical models were fitted to data from 19 years of fungicide trials, and log response ratio $(\bar{L})$ and approximate percent control $(\bar{C})$ relative to a nontreated check were estimated as measures of the effects of six treatments on FHB index (IND: mean percentage of diseased spikelets per spike) and DON. The evaluated treatments consisted of either Caramba (metconazole) applied early (at heading [CE]), at anthesis (CA), or late (5 to 7 days after anthesis; CL), or Prosaro (prothioconazole + tebuconazole) applied at the same three times and referred to as PE, PA, and PL, respectively. All treatments reduced mean IND and DON relative to the nontreated check, but the magnitude of the effect varied with timing and wheat type. CA

and PA resulted in the highest $\bar{C}$ values for IND, 52.2 and $51.5 \%$, respectively, compared with $45.9 \%$ for CL, $41.3 \%$ for PL, and less than $33 \%$ for $\mathrm{CE}$ and PE. Anthesis and postanthesis treatments reduced mean IND by 14.9 to $29.7 \%$ relative to preanthesis treatments. The estimated effect size was also statistically significant for comparisons between CA and CL and PA and PL; CA reduced IND by $11.7 \%$ relative to CL, whereas PA reduced the disease by $17.4 \%$ relative to PL. Differences in efficacy against IND between pairs of prothioconazole + tebuconazole and metconazole treatments applied at the same timing (CE versus $\mathrm{PE}, \mathrm{CA}$ versus $\mathrm{PA}$, and CL versus PL) were not statistically significant. However, CA and CL outperformed PA and PL by 7 and $12.8 \%$, respectively, in terms of efficacy against DON. All application programs had comparable efficacy against IND between spring and winter wheat types, but efficacy against DON was 10 to $16 \%$ greater for spring than winter wheat for applications made at or after anthesis. All programs led to an increase in mean grain yield and test weight relative to the nontreated check.
\end{abstract}

Fusarium head blight (Fusarium graminearum Schwabe) (FHB), an economically important disease of small grain crops, and its associated mycotoxin, deoxynivalenol (DON), are best managed by integrating strategies such as genetic resistance, a timely fungicide application, crop rotation, and tillage (Blandino et al. 2012; Lori et al. 2009; McMullen et al. 2008, 2012; Willyerd et al. 2012). A quantitative synthesis of data from more than 100 trials showed that when applied at anthesis, the demethylation inhibitor (DMI) fungicides metconazole (Caramba; BASF Corp., Research Triangle Park, NC), prothioconazole (Proline 480 SC; Bayer CropScience, Research Triangle Park, NC), and prothioconazole + tebuconazole (Prosaro; Bayer CropScience) provided between 45 and 52\% control of FHB index (IND) and DON (Paul et al. 2008). Subsequent analyses showed that the combination of an anthesis application of prothioconazole + tebuconazole and genetic resistance resulted in more than $70 \%$ reduction of both IND and DON, relative to the nontreated,

${ }^{\dagger}$ Corresponding author: P. A. Paul; E-mail: paul.661@osu.edu

Funding: Funding was provided by the U.S. Department of Agriculture. Salaries and research support for P. A. Paul, L. V. Madden, and F. D. DaSilva were provided by state and federal funds to the Ohio Agricultural Research and Development Center.

Accepted for publication 18 June 2018

(C) 2018 The American Phytopathological Society susceptible check (Willyerd et al. 2012). Furthermore, the effects of this combination were additive in terms of percent control.

Anthesis (Large 1954; Zadoks et al. 1974), characterized in wheat by the extrusion of anthers from the florets of the spike, has been previously accepted as the optimum growth stage for fungicide application for FHB control (Tateishi et al. 2014). Extrusion (Graham and Browne 2009; Kubo et al. 2013; Lu et al. 2013), retention (Buerstmayr et al. 2013), and fertility (Wang et al. 2015) of anthers, as well as flowering cleistogamy (Kubo et al. 2010), have all been shown to be associated with cultivar susceptibility to FHB and disease intensity. The process of anthesis is divided into three stages: early (Feekes 10.5.1; anthers extruded in the middle third of the spike [Zadoks GS60-61]), mid (Feekes 10.5.2; anthers extruded in the upper third of the spike [Zadoks GS64-65]), and late (Feekes 10.5.3; anthers extruded in the bottom third of the spike [Zadoks GS68-69]). Temporal variation is frequently observed in the development of tillers in the same field, with secondary tillers taking from a few to several days after primary tillers to reach anthesis. Consequently, anthesis at the plot or field scale is not a fixed point in time but rather a window that varies in length from a few to several days, depending on growing conditions, cultivar growing habit, crop production practices (row spacing, planting density, and fertility program), and complex interactions among these factors. However, because one must define a fixed time during the anthesis window for treatment application, anthesis is often considered to be reached when $50 \%$ of the primary tillers are at Feekes 10.5.1 (Zadoks GS60-61). This is also a commonly used criterion for recommending fungicide sprays for FHB management in commercial fields. 
However, for practical reasons, producers have not always been able to treat fields at the recommended early anthesis growth stage. For instance, because FHB is often most severe when it rains during anthesis, field conditions are frequently not conducive to ground applications when fungicides are most warranted. Although aerial application is a commonly used alternative, the fact that this is usually done by custom applicators means that treatments can be applied only when an aircraft becomes available, which may be before or after anthesis. These limitations have led to questions regarding the efficacy of pre- and postanthesis fungicide applications. Answers to these questions will determine if producers may have some flexibility in treating their fields either a few days before or after anthesis, without compromising FHB and DON management.

A few individual studies have investigated fungicide application timings for FHB and DON management in wheat, with results suggesting that the magnitude of the effect may depend on which fungicide is applied and the conditions under which any fungicide applications are made. However, most frequently, the highest levels of efficacy (percent control relative to a nontreated check) were observed for anthesis applications. For instance, evaluating preanthesis treatments of prothioconazole for FHB and DON management in winter wheat in the United Kingdom, Edwards and Godley (2010) showed that although applications at stem elongation (Zadoks GS31 [Feekes 6]) or full flag leaf emergence (Zadoks GS39 [Feekes 9]) reduced FHB incidence by 50 and $58 \%$ and DON by 27 and $49 \%$, respectively, the efficacy of a midanthesis (Zadoks GS65 [Feekes $10.5 .2]$ ) application was considerably higher, being $83 \%$ for incidence and $57 \%$ for DON. Based on a similar study on hard red spring wheat in Minnesota, Wiersma and Motteberg (2005) also reported that across several cultivars, tebuconazole (Folicur 3.6 F; Bayer CropScience) was more effective at reducing FHB when applied at early anthesis (Zadoks GS60 [Feekes 10.5.1]) than at GS39. Comparing anthesis and postanthesis applications of thiophanate-methyl (Topsin M; Nippon Soda Co., Chiyodaku, Tokyo) in Japan, Yoshida et al. (2012) observed that a single anthesis application reduced FHB severity by $82 \%$ in 2005 and $36 \%$ in 2006, compared with untreated checks. Contrastingly, treatments applied at 10 days after anthesis only reduced severity by $25 \%$ in the first year and $17 \%$ in the second, but the effect of this treatment was not statistically significant.

In one of the first published studies to compare the effects of anthesis and postanthesis applications of the fungicides prothioconazole + tebuconazole and metconazole on FHB and DON in soft red winter wheat in the U.S. Midwest, D'Angelo et al. (2014) reported that postanthesis treatments were just as or more efficacious (based on percent control) than anthesis treatments, in both naturally infected and inoculated trials. Based on a meta-analysis of data from field trials conducted in Ohio and Illinois from 2011 to 2013, they observed that relative to a nontreated check, applications made 2 days after anthesis resulted in the highest percent control of both IND and DON, 69 and $54 \%$, respectively, followed by applications at 4 (62 and 52\%) and $6(62$ and 48\%) days after anthesis, and at anthesis (56 and 50\%). Postanthesis applications reduced IND by up to $30 \%$, relative to the anthesis application, but for DON, the corresponding differences were not statistically significant. The authors further observed that the greatest difference in efficacy between anthesis and postanthesis treatments occurred when conditions were cool in the days leading up to anthesis or when it rained during the application of the anthesis treatments. This led them to hypothesize that weather conditions between heading and early grain-fill affected efficacy by changing the length of the anthesis window and flowering synchrony and that rainfall affected efficacy by reducing fungicide deposition and coverage.

The results of the study by D'Angelo et al. (2014) led us to question whether the efficacy of postanthesis applications would vary between winter and spring wheats, given that in most northern winter wheat growing regions the crop reaches anthesis in the spring when conditions are relatively cool, whereas in spring wheat production regions anthesis is reached in the summer, and generally under warmer conditions than those of winter wheat. Although the infection process and FHB development are generally considered to be similar across growing regions and market classes, some aspects of epidemiology and management of this disease-toxin complex have previously been shown to vary between winter and spring wheats. For instance, results from studies conducted in the United States showed that wheat type (spring versus winter) had a significant effect on the efficacy of several DMI fungicides (including prothioconazole + tebuconazole and metconazole) against IND and DON (Paul et al. 2007, 2008) and that relationships between visual estimates of FHB and DON varied between spring and winter wheat classes (Paul et al. 2005, 2006), as did functional relationships between IND and grain yield (Madden and Paul 2009). Based on these findings and for reasons related to differences in growing conditions between spring and winter wheats, we hypothesized that the effects of pre- and postanthesis applications on FHB and DON would vary between the wheat types and growing regions.

In this study we analyzed a data set consisting of 292 trials conducted over 19 years to revisit the question of pre- and postanthesis fungicide options for FHB and DON management in wheat. Focusing on the two most effective DMI fungicides, metconazole and prothioconazole + tebuconazole (Paul et al. 2008), we have expanded on the work done by D'Angelo et al. (2014) by conducting a more comprehensive analysis of data from a wider range of environments and wheat market classes. This has allowed us to evaluate the efficacy and variability of FHB and DON responses to these fungicides, as well as the effects of location- or region-specific factors on efficacy. The specific objectives were to (i) quantify and compare the efficacy of pre- and postanthesis applications of prothioconazole + tebuconazole and metconazole against FHB and DON in terms of mean percent control relative to a nontreated check, (ii) determine whether there was an overall gain or loss in efficacy with pre- and postanthesis applications relative to standard anthesis applications, (iii) compare the effects of anthesis and pre- and postanthesis treatments on grain yield and test weight, and (iv) determine whether wheat type, as a moderator variable, affected mean responses relative to the nontreated check. These were accomplished through network metaanalyses (Madden et al. 2016).

\section{Materials and Methods}

Uniform fungicide trials. From 1995 to 2013, more than 290 uniform fungicide trials (UFTs) supported by the U.S. Wheat and Barley Scab Initiative were conducted in 16 U.S. soft and hard wheatproducing states (AR, IA, IL, IN, KY, LA, MD, MI, MN, MO, ND, NY, OH, SD, VA, and WI) (Fig. 1). The initial set of UFTs (conducted from 1995 to 2007) evaluated and compared the effects of different active ingredient (AI), formulations and rates of AI on FHB development, DON accumulation, grain yield, and test weight (Hershman and Milus 2002; McMullen et al. 1999; Paul et al. 2007,2008 , 2010). Subsequent trials investigated the effects of different combinations of demethylation inhibitor (DMI) and quinone outside inhibitor (QoI) fungicides on FHB and DON when applied as a premix, a tank mix, or sequentially (Paul et al. in press). In addition, over the 19 years of UFTs, several treatments were incorporated or entire trials were established to evaluate the efficacy of pre- and postanthesis applications of QoI and DMI fungicides against FHB and DON (Bradley et al. 2009, 2010). Here we focus on this latter group of treatments.

Six UFT treatments, plus a nontreated check, were considered in this investigation. These consisted of metconazole and prothioconazole + tebuconazole applied individually at Feekes growth stages 10.5 (50\% full head emergence), 10.5 .1 (50\% early anthesis), or between 5 to 7 days after $50 \%$ early anthesis. All timings were based on the developmental stage of primary tillers (main stems). Prior to 2008, prothioconazole + tebuconazole and metconazole were tested as experimental products under various code names, and in some years, prothioconazole + tebuconazole was prepared by tank mixing tebuconazole and prothioconazole (Folicur 3.6 F and Proline 480 SC, respectively; Bayer CropScience) (Paul et al. 2008). For this paper, Feekes 10.5 treatments will be considered as early or preanthesis applications and hereafter abbreviated as CE and PE for metconazole and prothioconazole + tebuconazole, respectively, whereas treatments applied after $50 \%$ Feekes 10.5 .1 will be considered as postanthesis 
or late applications and abbreviated as CL and PL, respectively. Treatments applied at $50 \%$ early anthesis will be considered anthesis treatments and abbreviated as CA for metconazole and PA for prothioconazole + tebuconazole. Prothioconazole + tebuconazole was applied at a rate of $100 \mathrm{~g}$ of each AI per hectare, whereas metconazole was used at $92 \mathrm{~g}$ of $\mathrm{AI} / \mathrm{ha}$. All treatments were applied along with a nonionic surfactant, at spray volumes ranging from 94 to 197 liters/ha, using either backpack or tractor-mounted sprayer equipment. The total number of trials in which each treatment was evaluated for IND, DON, grain yield, and test weight is shown in Figure 2.

Details pertaining to plot dimensions, cultivar characteristics, agronomic practices, inoculation, and disease assessment can be found in Paul et al. (2007, 2008, 2010). In brief, plots of a susceptible wheat cultivar were planted in all trials in a randomized complete block design, with 4 to 6 replicate blocks. Plot dimensions ranged in width from 1.5 to $3 \mathrm{~m}$ and length from 6 to $10.7 \mathrm{~m}$. To enhance spore production, F. graminearum infection, and FHB development, plots were either planted after a $F$. graminearum-susceptible host crop (corn or wheat), artificially infested with $F$. graminearum-colonized grain spawn, or spray inoculated with a suspension of $F$. graminearum macroconidia or a mixture of macroconidia and ascospores 24 to $36 \mathrm{~h}$ after the anthesis-timed fungicide treatments were applied, and then mist irrigated during anthesis and early grain-fill. Of these approaches, the combination of colonized grain spawn and mist irrigation was the most commonly used across UFTs (Paul et al. 2007). IND was quantified as mean percentage of diseased spikelets per spike or estimated from FHB incidence and disease-head severity (Paul et al. 2005; Stack and McMullen 1998). DON contamination of grain, grain yield, and test weight were also quantified as previously described (Paul et al. 2007, 2008). Grain yield (adjusted to $13.5 \%$ moisture) was converted to kilograms per hectare $(\mathrm{kg} / \mathrm{ha})$ and test weight to kilograms per cubic meter $\left(\mathrm{kg} / \mathrm{m}^{3}\right)$ based on a 25-kg bushel weight.

Data analysis. Meta-analysis. Multitreatment or network metaanalytical models (Madden et al. 2016) were fitted to the data to estimate overall measures of efficacy of each treatment against IND and DON, to obtain overall mean estimates of yield and test weight responses to each treatment, and to compare responses among early, late, and anthesis fungicide applications. Although the six treatments of interest were not included in every UFT, the meta-analytical models were still fitted to the entire dataset. As discussed by Madden et al. (2016), using all the data allowed us to obtain direct as well as indirect evidence of treatment effects. A two-stage approach was used for all analyses. In the first stage, linear mixed models were fitted in

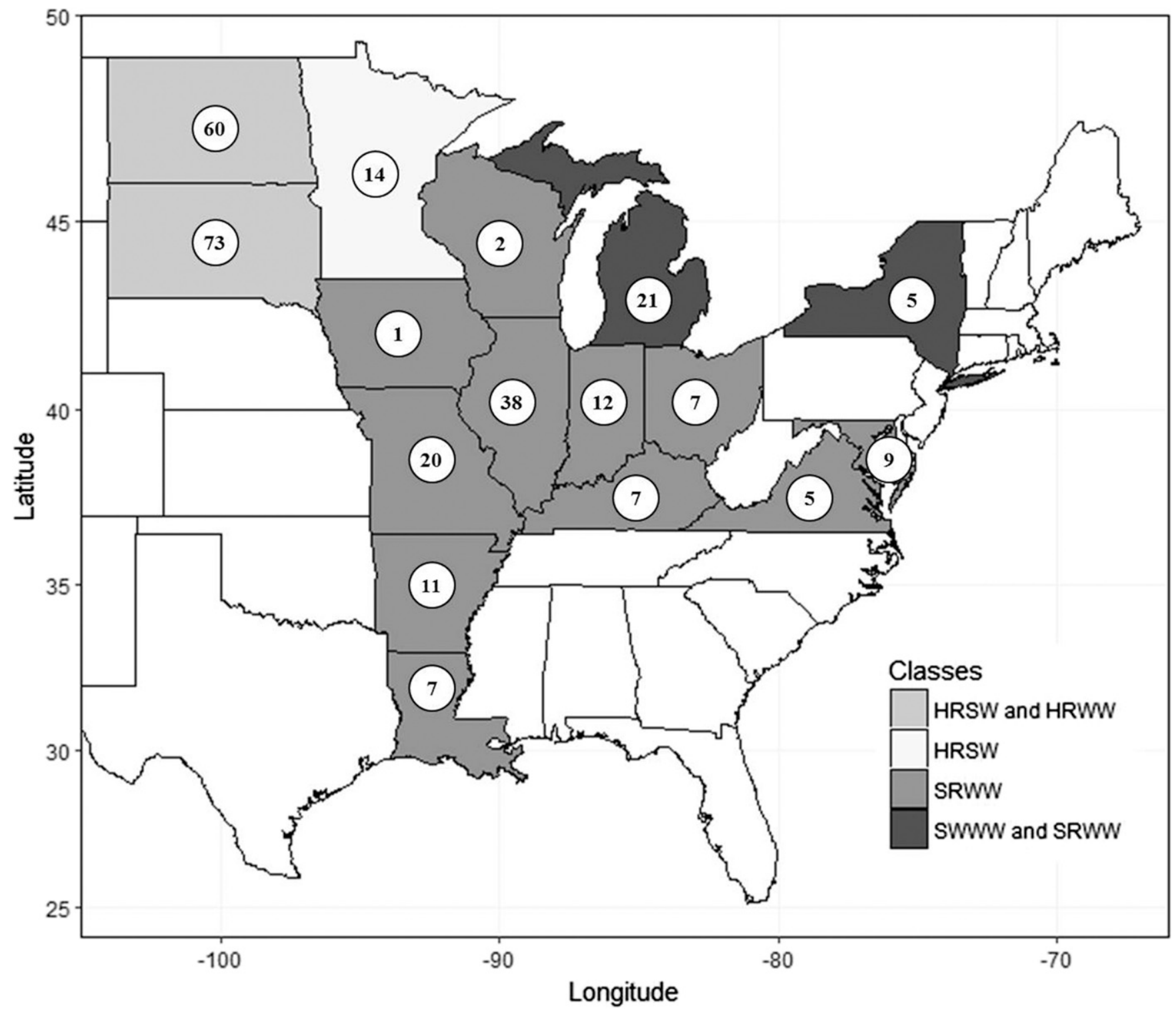

Fig. 1. Map showing states from which data were collected for this study. Shades of gray indicate soft red winter (SRWW), soft white winter (SWWW), hard red winter (HRWW), and hard red spring (HRSW) wheat market classes. Numbers are the number of uniform fungicide trials included from each of the participating states. 
PROC GLIMMIX of SAS (SAS, Cary, NC), with fungicide treatment as the fixed effect and block as the random effect. Each trial, and for a given trial, each response (IND, DON, yield, and test weight), was analyzed separately, and the lsmeans statement in GLIMMIX was used to estimate least squares means for each treatment. Residual variances were also estimated for each response in each trial and combined with the least squares means to construct a data matrix that was used in stage 2 of the analyses. The matrix was completed with data for the state and year in which the trial was conducted and the market class and type of the cultivar used.

In the second stage of the analysis, a two-way unconditional linear mixed modeling approach was used to fit the network meta-analytical models (model R5 in Madden et al. [2016]) using the GLIMMIX procedure of SAS, with restricted maximum likelihood as the parameter estimation method (Littell et al. 2006). Overall mean log response ratios $(\bar{L})$ and mean differences $(\bar{D})$ were estimated as the effect sizes to determine fungicide effects on IND and DON and on grain yield and test weight, respectively. Details of the meta-analytical modeling approach can be found in Madden et al. (2016) and van Houwelingen et al. (2002), and complete examples of its application for estimating $\log$ response ratios and mean differences as effect sizes, as well as $\hat{\sigma}^{2}$, are shown in Paul et al. (2008) and Paul et al. (2010), respectively. In brief, for IND and DON, vectors of log-transformed treatment means were constructed for each study, as well as the within-trial sampling variances for the log means in each study (determined using the method described on page 1001 of Paul et al. [2008]), the latter being held fixed in the network meta-analysis. Models were then fitted, and $\bar{L} s$, together with their standard errors and confidence intervals (CIs), were estimated by way of lsmestimate and lsmeans (with the diff option) statements in PROC GLIMMIX. Differences between pairs of $\log$ means are $\bar{L}$ s, because the log of the ratio is equal to the difference of the logs. Additionally, the between-trial variances were estimated for the $\log$ ratios and mean differences $\left(\hat{\sigma}^{2}\right)$ based on the estimated components of the between-trial variance-covariance matrix (see page 1003 in Paul et al. [2008] for details).
For grain yield and test weight, vectors of least squares treatment means were constructed for each trial, and lsmestimate and lsmeans statements in GLIMMIX were utilized to obtain the contrast estimates for pairs of treatments ( $\bar{D}$ values), as well as their associated standard errors and 95\% CIs. For all measured responses (IND, DON, yield, and test weight), specific contrasts were constructed and corresponding measures of precision (standard errors and CIs) estimated to evaluate the efficacy of each of the six treatments relative to the check, the efficacy of early and late applications relative to the anthesis application, and comparison of prothioconazole + tebuconazole with metconazole at each application time. Estimated mean percent control $(\bar{C})$ for IND and DON (reduction in the response relative to the check) and their 95\% CIs were then estimated for all contrasts of interest from $\bar{L}$ and the upper and lower limits of the 95\% CI around $\bar{L}$ as $[1-\exp (\bar{L})] \times 100$. Because it is a back transformation, $\bar{C}$ corresponds exactly to the median percent control, but because this value is close to the mean, we refer to it as the mean. Analysis was done directly on logs and not on percent control from each study because ratios (that comprise the percentage) have poor statistical properties (Madden and Paul 2011).

Influence of wheat type on the effect sizes. The network metaanalytical models were refitted to the data, with wheat type as a categorical moderator variable and fixed effect in the analyses. Trials were categorized and coded as either a winter (W) or spring $(\mathrm{S})$ wheat trial on the basis of the wheat market class planted. All soft red winter wheat, hard red winter wheat, and soft white winter wheat trials were coded $\mathrm{W}$ for winter wheat types, whereas hard red spring wheat and durum wheat trials were coded as $\mathrm{S}$ for spring wheat types. The model-fitting process and estimation of $\bar{L}$ and $\bar{C}$ and their standard errors and $95 \%$ CIs were as described above for the analysis without the moderate variable and in Paul et al. $(2008,2010)$. However, instead of estimating a single effect size for each contrast of interest, a pair of effect sizes was estimated, one for spring wheat and another for winter wheat (the two levels of the moderator variable) by way of lsmestimate and lsmeans/diff (or estimate) statements. Through
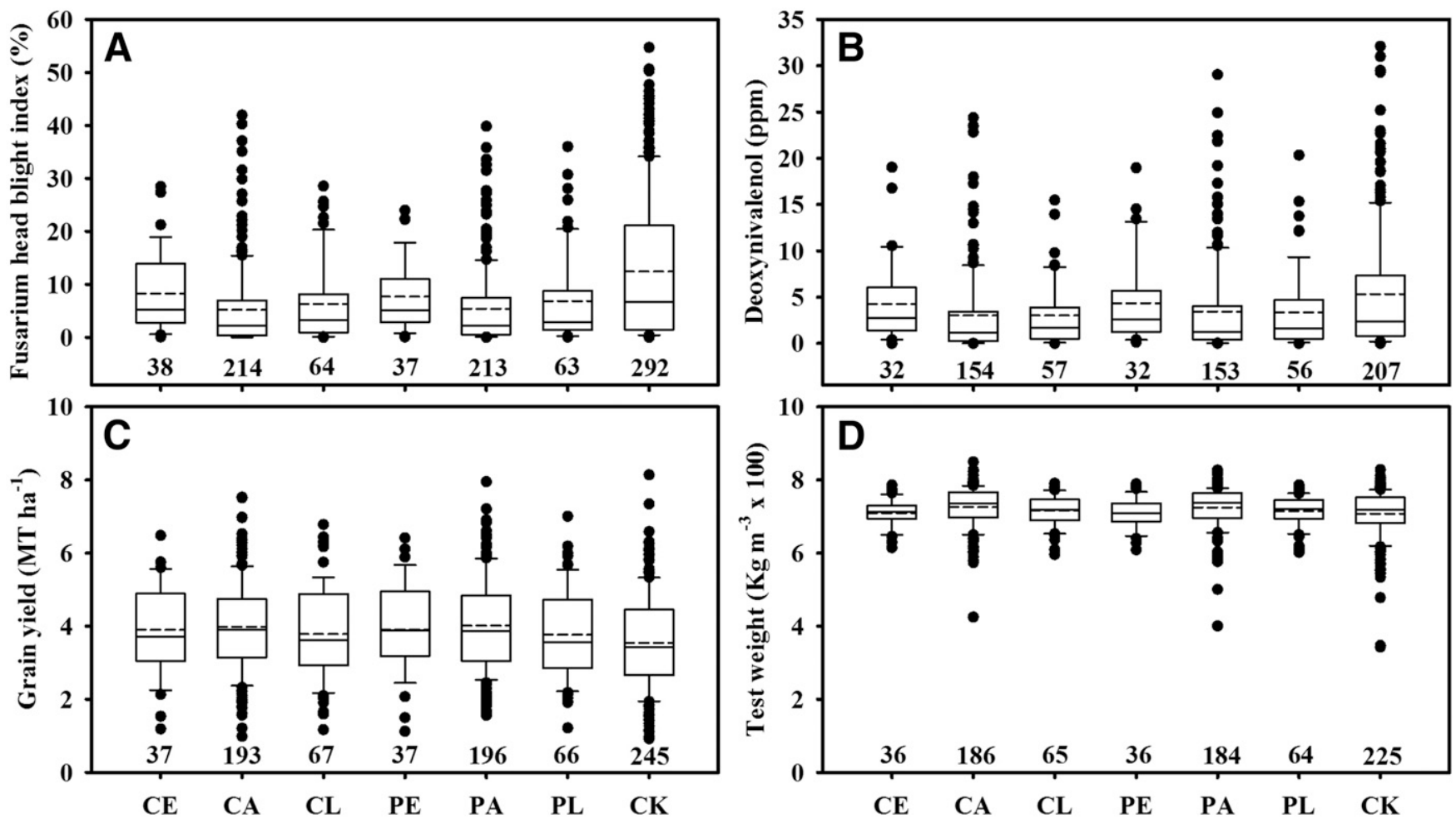

Fig. 2. Box plots summarizing the distribution of Fusarium head blight index (mean percentage of diseased spikelets per spike) (A), deoxynivalenol content of harvested wheat grain (B), and grain yield (C) and test weight (D) for different fungicide treatments plus a nontreated check (CK). Treatments were prothioconazole + tebuconazole applied before (PE), at $(\mathrm{PA})$, and after (PL) 50\% early anthesis (Feekes 10.5.1) and metconazole before (CE), at (CA), and after (CL) early anthesis. Broken and solid lines within each box represent means and medians, respectively, while the top and bottom lines of the box represent the 75th and 25th percentiles of the data, respectively. Vertical bars extending beyond the boxes represent the 10th and 90 th percentiles, and circles represent outliers. 
contrast and lsmestimate statements in GLIMMIX, $F$ tests were then used to determine whether wheat type had a significant effect on the $\log$ response ratios (differences in logs of IND or DON between pairs of treatments).

\section{Results}

Treatment effects on IND, DON, grain yield, and test weight. Summary statistics. Within-trial least squares means of IND, DON, yield, and test weight varied among treatments and trials (Fig. 2). For the nontreated check, used here as a measure of baseline values for all measured responses, $50 \%$ of the mean IND and DON values were between 1.5 and $21 \%$ and 0.8 and $7 \mathrm{ppm}$, respectively. The highest baseline IND level across 292 trials was 54\%, and for DON the highest baseline level across 207 trials was 32 ppm (Fig. $2 \mathrm{~A}$ and $\mathrm{B})$. Among the treatments, the overall means and interquartile ranges (IQR; difference between the first and third quartiles of the data) for both responses were highest for those applied prior to anthesis, PE and CE. Baseline grain yield ranged from 0.9 to $8 \mathrm{MT} / \mathrm{ha}$, with $50 \%$ of the data between 2.7 and $4.4 \mathrm{MT} /$ ha (Fig. 2C). The IQRs were comparable among treatments, ranging from 1.6 to $1.9 \mathrm{MT} / \mathrm{ha}$. For test weight, baseline values ranged from 340 to $830 \mathrm{~kg} / \mathrm{m}^{3}$, and $50 \%$ of the data were between 680 and $750 \mathrm{~kg} / \mathrm{m}^{3}$. The IQRs ranged from $34 \mathrm{~kg} / \mathrm{m}^{3}$ for the early metconazole (CE) treatment to $69 \mathrm{~kg} / \mathrm{m}^{3}$ for the two anthesis treatments, PA and CA (Fig. 2D).

Log response ratio and percent control for IND and DON. All fungicide treatments reduced mean IND and DON, relative to the nontreated check. For IND, the estimated effective sizes $(\bar{L})$ were negative (indicating a reduction compared with the check) and significantly different from zero $(P<0.05$; Tables 1 and 2$)$, with the highest negative values for the anthesis treatments (CA and PA), followed by the postanthesis treatments (PL and CL), and preanthesis treatments (CE and PE). Correspondingly, $\mathrm{CA}$ and PA resulted in the highest percent control, 52.2 and $51.5 \%$, respectively, compared with $45.9 \%$ for CL, $41.3 \%$ for PL, and less than $33 \%$ for CE and PE (Table 1). For both fungicides, anthesis and postanthesis treatments resulted in significantly lower IND than preanthesis treatments, that is, $\bar{L}$ values were negative and significantly different from zero $(P<0.05)$ for contrasts between $\mathrm{CA}$ and $\mathrm{CE}, \mathrm{CL}$ and $\mathrm{CE}, \mathrm{PA}$ and $\mathrm{PE}$, and PL and PE. Anthesis and postanthesis treatments reduced mean IND by 14.7 to $29.7 \%$ relative to preanthesis treatments. The estimated effect size was also statistically significant for comparisons between CA and CL and PA and PL; CA reduced IND by $11.7 \%$ relative to $\mathrm{CL}$, whereas $\mathrm{PA}$ reduced IND by $17.4 \%$ relative to PL (Table 1). Differences between pairs of prothioconazole + tebuconazole and metconazole treatments (CE versus PE, CA versus PA, and CL versus PL) were not statistically significant.

DON results were comparable to those observed for IND (Table 2), albeit with higher $\bar{L}$ and smaller $\bar{C}$ values overall. The estimated effect sizes were negative and significantly different from zero for all treatments $(P<0.05)$. Anthesis and postanthesis treatments again had higher negative $\bar{L}$ values and, correspondingly, resulted in greater DON reduction relative to the nontreated check $(\bar{C})$ than preanthesis treatments. $\bar{C}$ was 42.5 and $45.4 \%$ for CA and CL, respectively, 38.2 and $37.4 \%$ for PA and PL, respectively, and less than $26 \%$ for both CE and PE. Anthesis and postanthesis treatments reduced mean DON relative to preanthesis treatments by 27.1 and $30.7 \%$, respectively, for metconazole, and 17 and $15.9 \%$, respectively, for prothioconazole + tebuconazole. Effect sizes for contrasts between anthesis and postanthesis applications of prothioconazole + tebuconazole (PA versus PL) or metconazole (CA versus $\mathrm{CL})$ were not statistically significant. However, $\bar{L}$ values were significantly different from zero for comparisons between the two fungicides for applications made at anthesis (CA versus PA) or after (CL versus PL). CA resulted in $7 \%$ lower DON than PA, and CL in $12.8 \%$ lower DON than PL (Table 2).

Mean differences for grain yield and test weight. For both grain yield and test weight, the overall mean difference relative to the nontreated check, the effect size $(\bar{D})$, was positive and significantly different from zero for all treatments $(P<0.05$, Table 3$)$, indicating that yield and test weight were higher in all treatments compared with the nontreated check. Every treatment resulted in more than a $330 \mathrm{~kg} / \mathrm{ha}$ increase in yield, with the highest $\bar{D}$ values for the anthesis treatments, PA (431.6 kg/ha) and CA $(398.6 \mathrm{~kg} / \mathrm{ha})$, followed by CL (358 kg/ha). $\bar{D}$ was not statistically significant for any of the pairwise comparisons between metconazole treatments; yield differences were only between 20.6 and $61.2 \mathrm{~kg} / \mathrm{ha}$. However, for prothioconazole + tebuconazole, the anthesis treatment (PA) resulted in close to $100 \mathrm{~kg} / \mathrm{ha}$ higher yield than pre- or postanthesis treatments. $\bar{D}$ was not significantly different from zero $(P>0.05$, Table 3$)$ for comparisons between pairs of prothioconazole + tebuconazole and metconazole treatments applied at the same growth stage (CE versus $\mathrm{PE}, \mathrm{CA}$ versus $\mathrm{PA}$, or CL versus PL).

The test weight results followed a similar pattern to those observed for grain yield; all treatments resulted in a significant increase in test weight relative to the nontreated check $(P<0.05$; Table 3$) . \bar{D}$ values were higher for anthesis (PA and CA) and postanthesis (PL and CL) treatments $\left(16.0\right.$ to $\left.17.7 \mathrm{~kg} / \mathrm{m}^{3}\right)$ than for preanthesis treatments (approximately $11 \mathrm{~kg} / \mathrm{m}^{3}$ for $\mathrm{PE}$ and $\mathrm{CE}$ ) and significantly different from zero for comparisons between anthesis and preanthesis treatments and between pre- and postanthesis treatments, but not between anthesis and postanthesis or between pairs of prothioconazole + tebuconazole and metconazole treatments $(P>0.05$, Table 3$)$.

Influence of wheat type on the efficacy of fungicide treatments against IND and DON. For IND and DON, in both spring and winter wheat, preanthesis, anthesis, and postanthesis applications of prothioconazole + tebuconazole and metconazole all resulted in significantly lower mean levels of disease and toxin than the nontreated check. All effect sizes $(\bar{L})$ were negative and significantly different from zero $(P<0.001$, Table 4$)$. The relative efficacy of the treatments was comparable to that observed for the combined data set (without moderator variable), with anthesis and postanthesis applications resulting in higher negative $\bar{L}$ values and, consequently, higher mean percent control than preanthesis applications in both spring and winter wheat. For IND, the effect of wheat type was not statistically significant $(P>0.05$; Table 4$)$ for any of the tested treatments; that is, the magnitude of the effect of a treatment on IND did not depend on wheat type.

All treatments reduced mean DON relative to the nontreated check in both winter and spring wheat (statistically significant effect sizes in Table 4), but contrary to what was observed for IND, wheat type had a statistically significant effect on the efficacy of anthesis (PA and CA) and postanthesis (PL and CL) treatments but not preanthesis treatments (PE and $\mathrm{CE}$ ). Based on $F$ tests from the analyses, differences between pairs of log response ratios for comparisons of the efficacy of CA, PA, CL, and PL between spring and winter wheat were statistically significant $(P<0.05$, Table 4$)$. Estimated mean effect sizes and, correspondingly, mean percent control values were significantly higher in spring wheat than in winter wheat for CA, PA, CL, and PL. For instance, PA and CA resulted in 10.1 and $10.8 \%$ lower DON than the mean for the nontreated check in spring wheat than in winter wheat, respectively. Similarly, percent DON reduction relative to the check was $9.9 \%$ higher for CL and $15.6 \%$ higher for PL in spring wheat than in winter wheat.

Predicted efficacy against IND and DON in future studies. Using effect sizes from the meta-analysis $(\bar{L})$ and their respective between study variances $\left(\hat{\sigma}^{2}\right)$, probabilities of achieving a certain level of IND or DON control in a new randomly selected study, conducted in a manner similar to the studies described herein, were estimated for all tested fungicide treatments (Fig. 3). For example, the probability of at least a $50 \%$ control $(\bar{C}>50 \%)$ of IND or DON, equivalent to the probability that $\bar{L}<-0.69$, was estimated as follows:

$$
p_{50}=\varnothing(-0.69-\bar{L}) / \sqrt{\hat{\sigma}^{2}}
$$

where $\varnothing(\bullet)$ is the cumulative standard-normal function (Paul et al. $2008,2010)$. So, with an estimated effect size of -0.76 and between study variance of 0.185 for the effect of CA on IND in spring wheat (Table 4$), p_{50}$ was estimated as $\varnothing(-0.69+0.76) / 0.43=$ 0.56 . Similarly, the $\bar{L}$ and $\hat{\sigma}^{2}$ values in Table 4 were used to estimate 
probabilities of each treatment resulting in between 2 and $50 \%$ lower mean IND or DON than the mean for the nontreated check in spring and winter wheat.

The probability of IND or DON being reduced by a certain percentage decreased for all treatments as the projected percent control increased from 2 to $50 \%$ (Fig. 3). For spring wheat, anthesis treatments consistently had the highest estimated probabilities for IND, followed by postanthesis, and then the preanthesis treatments. For instance, the estimated probability of achieving at least a $25 \%$ IND reduction $\left(p_{25}\right)$ in a new spring wheat trial was $\geq 0.80$ for CA (0.86), CL (0.80), PA (0.82), and PL (0.80), compared with 0.53 for $\mathrm{CE}$ and 0.61 for PE (Fig. 3A). For winter wheat, $p_{25}$ was 0.83 for PA, 0.85 for CA and CL, and 0.71 for PL (Fig. 3B). Interestingly, the probability of achieving a percent control of $25 \%$ or greater with a preanthesis application varied considerably between wheat types and depended on the fungicide applied. For instance, with CE, there was a $49 \%$ chance of seeing a $40 \%$ reduction in IND relative to the check in winter wheat $\left(p_{40}=0.49\right)$ compared with only a $28 \%$ chance

Table 1. Overall mean effect sizes (log response ratios), percent control, and corresponding statistics for the effect of fungicide treatments on Fusarium head blight index (mean percentage of diseased spikelets per spike) in wheat

\begin{tabular}{|c|c|c|c|c|c|c|c|c|}
\hline \multirow[b]{2}{*}{ Contrast $^{\mathbf{a}}$} & \multicolumn{5}{|c|}{ Effect size $^{\mathbf{b}}$} & \multicolumn{3}{|c|}{ Mean percent control ${ }^{c}$} \\
\hline & $\bar{L}$ & $\operatorname{se}(\bar{L})$ & $C I_{L}$ & $C I_{U}$ & $P$ & $\bar{C}$ & $C I_{L}$ & $C I_{U}$ \\
\hline \multicolumn{9}{|c|}{ Between treatment and CK } \\
\hline CE versus CK & -0.40 & 0.056 & -0.51 & -0.29 & $<0.001$ & 32.78 & 25.03 & 39.72 \\
\hline $\mathrm{CA}$ versus $\mathrm{CK}$ & -0.74 & 0.038 & -0.81 & -0.67 & $<0.001$ & 52.23 & 48.57 & 55.64 \\
\hline CL versus CK & -0.61 & 0.048 & -0.71 & -0.52 & $<0.001$ & 45.93 & 40.64 & 50.75 \\
\hline$P E$ versus $C K$ & -0.37 & 0.053 & -0.48 & -0.27 & $<0.001$ & 31.00 & 23.43 & 37.83 \\
\hline PA versus $\mathrm{CK}$ & -0.72 & 0.039 & -0.80 & -0.65 & $<0.001$ & 51.51 & 47.64 & 55.09 \\
\hline PL versus CK & -0.53 & 0.044 & -0.62 & -0.45 & $<0.001$ & 41.29 & 36.05 & 46.09 \\
\hline \multicolumn{9}{|c|}{ Between application timings } \\
\hline $\mathrm{CA}$ versus $\mathrm{CE}$ & -0.34 & 0.053 & -0.45 & -0.24 & $<0.001$ & 28.95 & 21.09 & 36.02 \\
\hline CA versus CL & -0.12 & 0.047 & -0.22 & -0.03 & 0.008 & 11.66 & 3.16 & 19.42 \\
\hline CL versus $C E$ & -0.22 & 0.059 & -0.33 & -0.10 & $<0.001$ & 19.57 & 9.61 & 28.42 \\
\hline $\mathrm{PA}$ versus $\mathrm{PE}$ & -0.35 & 0.054 & -0.46 & -0.25 & $<0.001$ & 29.72 & 21.92 & 36.74 \\
\hline PA versus PL & -0.19 & 0.045 & -0.28 & -0.10 & $<0.001$ & 17.41 & 9.80 & 24.38 \\
\hline PL versus PE & -0.16 & 0.059 & -0.28 & -0.05 & 0.006 & 14.91 & 4.54 & 24.14 \\
\hline \multicolumn{9}{|c|}{ Between fungicides } \\
\hline $\mathrm{CE}$ versus PE & -0.03 & 0.063 & -0.15 & 0.10 & 0.678 & 2.57 & -10.16 & 13.83 \\
\hline CA versus PA & -0.02 & 0.031 & -0.08 & 0.05 & 0.630 & 1.50 & -4.73 & 7.35 \\
\hline CL versus PL & -0.08 & 0.051 & -0.18 & 0.02 & 0.107 & 7.91 & -1.78 & 16.68 \\
\hline
\end{tabular}

${ }^{a}$ Nontreated check (CK), metconazole applied before (CE), at (CA), or after (CL) 50\% early anthesis (Feekes 10.5.1), and prothioconazole + tebuconazole applied before (PE), at (PA), or after (PL) early anthesis.

b $\bar{L}=$ mean log of the response ratio between pairs of treatments; $\operatorname{se}(\bar{L})=$ standard error of $\bar{L} ; P=$ significance level; and $C I_{U}$ and $C I_{L}=$ upper and lower limits of the $95 \%$ confidence interval around $\bar{L}$, respectively.

${ }^{c} \bar{C}=$ mean percent control was estimated from $\bar{L}$ as $\bar{C}=[1-\exp (\bar{L})] \times 100$; and $C I_{U}$ and $C I_{L}=$ upper and lower limits of the $95 \%$ confidence interval around $\bar{C}$, respectively.

Table 2. Overall mean effect size (log response ratio), percent control, and corresponding statistics for the effect of fungicide treatments on deoxynivalenol content of wheat grain

\begin{tabular}{|c|c|c|c|c|c|c|c|c|}
\hline \multirow[b]{2}{*}{ Contrast $^{\mathbf{a}}$} & \multicolumn{5}{|c|}{ Effect size ${ }^{b}$} & \multicolumn{3}{|c|}{ Mean percent control ${ }^{c}$} \\
\hline & $\overline{\boldsymbol{L}}$ & $\operatorname{se}(\bar{L})$ & $C I_{L}$ & $C I_{U}$ & $P$ & $\bar{C}$ & $C I_{L}$ & $C \boldsymbol{I}_{U}$ \\
\hline \multicolumn{9}{|c|}{ Between treatment and CK } \\
\hline $\mathrm{CE}$ versus $\mathrm{CK}$ & -0.24 & 0.037 & -0.31 & -0.17 & $<0.001$ & 21.17 & 15.32 & 26.62 \\
\hline CA versus CK & -0.55 & 0.034 & -0.62 & -0.49 & $<0.001$ & 42.52 & 38.52 & 46.26 \\
\hline CL versus $C K$ & -0.61 & 0.044 & -0.69 & -0.52 & $<0.001$ & 45.39 & 40.50 & 49.88 \\
\hline PE versus CK & -0.30 & 0.036 & -0.37 & -0.22 & $<0.001$ & 25.56 & 20.07 & 30.67 \\
\hline PA versus $C K$ & -0.48 & 0.031 & -0.54 & -0.42 & $<0.001$ & 38.19 & 34.34 & 41.82 \\
\hline PL versus CK & -0.47 & 0.038 & -0.54 & -0.39 & $<0.001$ & 37.40 & 32.56 & 41.90 \\
\hline \multicolumn{9}{|c|}{ Between application timings } \\
\hline $\mathrm{CA}$ versus $\mathrm{CE}$ & -0.32 & 0.040 & -0.39 & -0.24 & $<0.001$ & 27.08 & 21.12 & 32.59 \\
\hline CA versus $\mathrm{CL}$ & 0.05 & 0.038 & -0.02 & 0.13 & 0.175 & -5.26 & -13.36 & 2.25 \\
\hline CL versus $\mathrm{CE}$ & -0.37 & 0.047 & -0.46 & -0.28 & $<0.001$ & 30.72 & 24.04 & 36.82 \\
\hline $\mathrm{PA}$ versus $\mathrm{PE}$ & -0.19 & 0.040 & -0.26 & -0.11 & $<0.001$ & 16.97 & 10.19 & 23.23 \\
\hline PA versus PL & -0.01 & 0.034 & -0.08 & 0.05 & 0.711 & 1.26 & -5.61 & 7.69 \\
\hline PL versus PE & -0.17 & 0.044 & -0.26 & -0.09 & $<0.001$ & 15.91 & 8.24 & 22.93 \\
\hline \multicolumn{9}{|c|}{ Between fungicides } \\
\hline CE versus $\mathrm{PE}$ & 0.06 & 0.044 & -0.03 & 0.14 & 0.189 & -5.90 & -15.36 & 2.78 \\
\hline CA versus PA & -0.07 & 0.025 & -0.12 & -0.02 & 0.004 & 7.00 & 2.26 & 11.50 \\
\hline CL versus PL & -0.14 & 0.041 & -0.22 & -0.06 & 0.001 & 12.76 & 5.46 & 19.50 \\
\hline
\end{tabular}

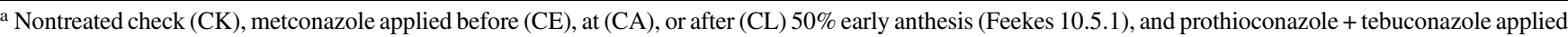
before (PE), at (PA), or after (PL) early anthesis.

${ }^{\mathrm{b}} \bar{L}=$ mean $\log$ of the response ratio between pairs of treatments; $\operatorname{se}(\bar{L})=$ standard error of $\bar{L} ; P=$ significance level; and $C I_{U}$ and $C I_{L}=$ upper and lower limits of the 95\% confidence interval around $\bar{L}$, respectively.

${ }^{c} \bar{C}=$ mean percent control was estimated from $\bar{L}$ as $\bar{C}=[1-\exp (\bar{L})] \times 100$; and $C I_{U}$ and $C I_{L}=$ upper and lower limits of the $95 \%$ confidence interval around $\bar{C}$, respectively. 
in spring wheat $\left(p_{40}=0.28\right)$ (Fig. 3A and B). Conversely, with PE, the probability of achieving a $40 \%$ control of IND was 0.38 in spring wheat and 0.30 in winter wheat.

For DON, the estimated probability of achieving a percent control of $25 \%$ or greater in a new randomly selected trial was considerably higher for anthesis and postanthesis treatments than for preanthesis treatments and was higher in spring wheat than winter wheat (Fig. $3 \mathrm{C}$ and D). For example, $p_{25}$ was $>0.80$ for CA (0.86), CL (0.89), PA (0.84), and PL (0.89) for spring wheat, compared with only 0.47 for CE and 0.64 for PE (Fig. 3C). The corresponding probabilities for winter wheat were $0.72,0.76,0.66$, and 0.62 for CA, CL, PA, and PL, respectively, and less than 0.45 for CE and PE (Fig. 3D). For both wheat types, the highest probability of achieving at least a $50 \%$ reduction in DON $\left(p_{50}\right)$ relative to the nonrelated check was observed for the postanthesis metconazole treatment (CL), but $p_{50}$ for CL was considerable higher in spring wheat, 0.53 , than winter wheat, 0.33 .

\section{Discussion}

For both metconazole and prothioconazole + tebuconazole, applications made before (referred to here as early or preanthesis), at, and after (referred to as late or postanthesis) $50 \%$ of the primary tillers reached Feekes 10.5.1 (referred to as anthesis) all reduced mean IND and DON relative to the nontreated check. This is consistent with findings from other studies investigating the effects of fungicide timing on FHB and DON (D'Angelo et al. 2014; Tateishi et al. 2014; Wegulo et al. 2011). Applications made before anthesis, and presumably before infection, given that plots were inoculated during anthesis, are considered as preventive (protective), whereas applications made after inoculation (and infection) are considered curative (Chen et al. 2012; Ivic 2010). Therefore, our results demonstrate that the tested fungicides have both preventive and curative effects against FHB and DON. This is not at all surprising because these are properties known to be characteristic of demethylation inhibitor (DMI) fungicides and have been demonstrated previously for metconazole (Tateishi et al. 2014) and related AIs (Boyacioglu et al. 1992; Chen et al. 2012). Although all treatment programs resulted in a statistically significant reduction in mean IND and DON relative to the nontreated check, the magnitude of the effects in terms of percent control (used here as a measure of efficacy) was dependent on the response (IND versus DON), application timing (before, at, or after anthesis), wheat type (winter versus spring wheat), and to a lesser extent, the specific fungicide (prothioconazole + tebuconazole versus metconazole).

For IND, treatments applied at anthesis (CA and PA) were the most effective, with an overall (across all trials) approximate percent control of $52 \%$ for both products, followed by those applied after anthesis (percent control of $46 \%$ for CL and $41 \%$ for PL). Treatments applied preventively (at or close to 50\% full head emergence; Feekes 10.5 ) were the least effective, with mean percent control of less than $33 \%$ for CE and PE. Based on percent control, calculated from contrasts of log-transformed means across trials, anthesis treatments reduced mean IND by 29 to $30 \%$, relative to preanthesis treatment, and by 12 to $17 \%$ relative to postanthesis treatments, whereas postanthesis treatments resulted in a 15 to $20 \%$ reduction in mean IND relative to preanthesis treatments. Like the treatments applied at heading, anthesis treatments were also done preventively, but the primary difference was that the latter were applied closer to the time of early anthesis, and consequently close to infection of spikes on primary tillers and a few days before infection of the first spikes on secondary tillers. Heading applications were made at least 5 days before infection of spikes on primary tillers and even earlier for spikes on secondary tillers. The success of a preventative treatment is related to the amount and persistence of AI on the plant surface before infection (Vicent et al. 2007). Because applications made well before infection were more subject to environment-, fungicide-, and host-related factors known to negatively affect fungicide persistence (Andersen et al. 2014; Hunsche et al. 2006; Vicent et al. 2007), the concentration of AIs on or in spikes treated at heading was likely reduced to less effective levels, leading to reduced efficacy when compared with anthesis treatments. Andersen et al. (2014) demonstrated that the half-life of tebuconazole on wheat spikes (time taken for residue to decrease by 50\%) was 6 to 9 days, depending on the growing season.

Based on results from a limited number of soft red winter wheat trials conducted under a narrow range of growing conditions, D'Angelo et al. (2014) showed that the efficacy of postanthesis treatments also depended on how late the applications were made after approximately $50 \%$ of the spikes on primary tillers reached early anthesis. They observed that curative applications closer to $50 \%$ early anthesis ( 2 days postanthesis) were more effective in reducing IND than those applied 4 or 6 days postanthesis. Similarly, Mauler-Machnik and Suty (1997) showed that the efficacy of tebuconazole was optimum when applied within a day or two of inoculation, and a longer interval

Table 3. Overall mean effect sizes (difference in grain yield and test weight) and corresponding statistics for the effect of fungicide treatments for Fusarium head blight management on grain yield and test weight

\begin{tabular}{|c|c|c|c|c|c|c|c|c|c|c|}
\hline \multirow[b]{2}{*}{ Contrast $^{\mathbf{a}}$} & \multicolumn{5}{|c|}{ Grain yield $^{b}$} & \multicolumn{5}{|c|}{ Test weight $^{\mathbf{b}}$} \\
\hline & $\bar{D}$ & $\mathbf{s e}(\bar{D})$ & $C I_{L}$ & $C \boldsymbol{I}_{U}$ & $P$ & $\bar{D}$ & $\operatorname{se}(\bar{D})$ & $C I_{L}$ & $C I_{U}$ & $P$ \\
\hline \multicolumn{11}{|c|}{ Between treatment and CK } \\
\hline CE versus CK & 337.41 & 40.21 & 258.55 & 416.28 & $<0.001$ & 11.21 & 1.83 & 7.61 & 14.81 & $<0.001$ \\
\hline CA versus $\mathrm{CK}$ & 398.62 & 22.05 & 355.38 & 441.87 & $<0.001$ & 16.18 & 1.65 & 12.94 & 19.42 & $<0.001$ \\
\hline CL versus $C K$ & 358.03 & 28.06 & 303.00 & 413.06 & $<0.001$ & 17.76 & 2.14 & 13.56 & 21.97 & $<0.001$ \\
\hline PE versus CK & 334.99 & 37.92 & 260.62 & 409.37 & $<0.001$ & 10.98 & 1.74 & 7.57 & 14.39 & $<0.001$ \\
\hline PA versus $\mathrm{CK}$ & 431.58 & 22.39 & 387.66 & 475.50 & $<0.001$ & 16.00 & 1.23 & 13.59 & 18.41 & $<0.001$ \\
\hline PL versus $C K$ & 333.97 & 28.34 & 278.38 & 389.55 & $<0.001$ & 17.23 & 2.00 & 13.31 & 21.14 & $<0.001$ \\
\hline \multicolumn{11}{|c|}{ Between application timings } \\
\hline $\mathrm{CA}$ versus $\mathrm{CE}$ & 61.21 & 37.70 & -12.73 & 135.15 & 0.105 & 4.97 & 1.58 & 1.86 & 8.08 & 0.002 \\
\hline CA versus $C L$ & 40.59 & 29.65 & -17.57 & 98.76 & 0.171 & -1.58 & 1.38 & -4.28 & 1.11 & 0.249 \\
\hline $\mathrm{CL}$ versus $\mathrm{CE}$ & 20.62 & 43.26 & -64.24 & 105.48 & 0.634 & 6.56 & 1.81 & 3.00 & 10.11 & $<0.001$ \\
\hline PA versus PE & 96.58 & 37.31 & 23.40 & 169.77 & 0.010 & 5.02 & 1.51 & 2.06 & 7.97 & 0.001 \\
\hline PA versus PL & 97.61 & 30.86 & 37.07 & 158.15 & 0.002 & -1.23 & 1.42 & -4.02 & 1.56 & 0.386 \\
\hline PL versus PE & -1.03 & 41.49 & -82.41 & 80.36 & 0.980 & 6.25 & 1.82 & 2.68 & 9.81 & 0.001 \\
\hline \multicolumn{11}{|l|}{ Between fungicides } \\
\hline CE versus $\mathrm{PE}$ & 2.42 & 46.46 & -88.72 & 93.56 & 0.959 & 0.23 & 1.84 & -3.38 & 3.84 & 0.901 \\
\hline $\mathrm{CA}$ versus $\mathrm{PA}$ & -32.95 & 18.88 & -69.98 & 4.07 & 0.081 & 0.18 & 1.00 & -1.77 & 2.14 & 0.853 \\
\hline CL versus PL & 24.06 & 32.07 & -38.83 & 86.96 & 0.453 & 0.54 & 1.41 & -2.24 & 3.31 & 0.704 \\
\hline
\end{tabular}

a Nontreated check (CK), metconazole applied before (CE), at (CA), or after (CL) 50\% early anthesis (Feekes 10.5.1), and prothioconazole + tebuconazole applied before (PE), at (PA), or after (PL) early anthesis.

${ }^{\mathrm{b}} \bar{D}=$ mean difference between pairs of treatments; se $(\bar{D})=$ standard error of $\bar{D} ; C I_{U}$ and $C I_{L}=$ upper and lower limits of the $95 \%$ confidence interval around $\bar{D}$, respectively; and $P=$ significance level. 
before or after infection sharply decreased efficacy. Although spikes on some late-developing primary tillers and secondary tillers were probably between early and last anthesis when the late curative treatments were applied, most of the primary spikes were probably already infected and at early grain-fill. Therefore, postanthesis treatments made between 5 and 7 days after $50 \%$ early anthesis of primary tillers were likely applied preventively to some but curatively to most of the spikes. The superior efficacy of anthesis treatments compared with postanthesis treatments suggests that the preventive applications made shortly before infection were more effective than predominantly curative applications made 5 days or more after the initial infection. However, when the two types of programs were compared at a similar number of days before or after anthesis, applications 5 to 7 days after infection, curatively, performed better than those made the same number of days before infection, preventively. This is consistent with results from a study conducted by Boyacioglu et al. (1992) to investigate the curative effects of propiconazole (Tilt 3.6 EC; Syngenta, Raleigh, NC) on FHB. They demonstrated that a curative application of propiconazole 2 days after inoculation with a spore suspension of $F$. graminearum $\left(1 \times 10^{5}\right.$ spores $\left./ \mathrm{ml}\right)$ was more effective (based on percent reduction of kernel infection relative to the nontreated check) than a preventive application made 2 days before inoculation.

The estimated efficacy of the two fungicides evaluated was generally comparable when applications were made before, at, or after anthesis. However, there was a trend toward higher efficacy for metconazole over prothioconazole + tebuconazole for late applications. D'Angelo et al. (2014) also alluded to numerically higher efficacy for postanthesis applications of metconazole over postanthesis applications of prothioconazole + tebuconazole. In the current study, this difference became larger and statistically significant when DON was used as a measure of treatment effect. As was the case with IND, all treatments led to a significant reduction in mean DON relative to the nontreated check, but the magnitude of the effect not only depended on when the fungicide was applied relative to anthesis but also the AI of the fungicide applied. Postanthesis applications were just as effective as anthesis applications against DON, and they were both more effective than preanthesis applications, likely for some of the same reasons discussed above for IND. Percent control values for anthesis applications were within the range of values previously reported from a meta-analysis of a smaller subset of the UFT data used in this study (Paul et al. 2008). However, here we observed a $7 \%$ higher efficacy against DON for metconazole over prothioconazole + tebuconazole for applications made at anthesis, which was slightly higher than the difference of 3 to $4 \%$ report by Paul et al. (2008). A larger difference in efficacy (12.8\%) between the two was observed for applications made at 5 to 7 days after $50 \%$ of the spikes on primary tillers were at early anthesis. Differences in terms of absorption, redistribution, persistence, and curative effect are possible reasons for the observed difference in estimated efficacy between metconazole and prothioconazole + tebuconazole. Similar differences among DMI fungicides in terms of their curative effects have been reported for other pathosystems (Holb and Schnabel 2007; Schnabel et al. 2004; Schöfl and Zinkernagel 1997).

The effect of wheat type on fungicide efficacy against IND was not statistically significant for any of the fungicide $\times$ application timing combinations evaluated. Trends in winter and spring wheat in terms of the magnitude and significance of treatment effects relative to the nontreated check and relative to anthesis treatments were very similar to those discussed for the general situation (when efficacy was estimated for the entire dataset without regard for wheat type). These results suggest that differences in growing conditions between spring and winter wheat regions likely did not impact the relative performance of metconazole and prothioconazole + tebuconazole applications made before, at, or after anthesis in terms of their ability to reduce the development of visual symptoms. Estimated mean percent

Table 4. Overall mean log response ratios (effect sizes), percent control, and corresponding statistics for the influence of wheat type on the effects of fungicides on Fusarium head blight index and deoxynivalenol in wheat

\begin{tabular}{|c|c|c|c|c|c|c|c|c|c|c|c|}
\hline \multirow[b]{2}{*}{ Response $^{\mathbf{a}}$} & \multirow[b]{2}{*}{ Contrast $^{\mathbf{b}}$} & \multirow[b]{2}{*}{ Type $^{\mathrm{c}}$} & \multicolumn{6}{|c|}{ Effect size ${ }^{d}$} & \multicolumn{3}{|c|}{ Mean percent control ${ }^{\mathrm{e}}$} \\
\hline & & & $\bar{L}$ & $\mathbf{s e}(\bar{L})$ & $C I_{L}$ & $\boldsymbol{C I}_{U}$ & $\hat{\sigma}^{2}$ & $P$ & $\overline{\boldsymbol{C}}$ & $C I_{L}$ & $\boldsymbol{C I}_{U}$ \\
\hline \multirow[t]{12}{*}{ IND } & \multirow[t]{2}{*}{$\mathrm{CE}$ versus $\mathrm{CK}$} & Spring & $-0.31 * *$ & 0.074 & -0.46 & -0.16 & 0.119 & 0.072 & 26.61 & 15.08 & 36.58 \\
\hline & & Winter & $-0.50 * *$ & 0.075 & -0.65 & -0.35 & & & 39.33 & 29.71 & 47.63 \\
\hline & \multirow[t]{2}{*}{$\mathrm{CA}$ versus $\mathrm{CK}$} & Spring & $-0.76^{* *}$ & 0.054 & -0.87 & -0.66 & 0.185 & 0.631 & 53.32 & 48.15 & 57.98 \\
\hline & & Winter & $-0.73^{* *}$ & 0.051 & -0.83 & -0.63 & & & 51.63 & 46.51 & 56.25 \\
\hline & \multirow[t]{2}{*}{$\mathrm{CL}$ versus $\mathrm{CK}$} & Spring & $-0.59 * *$ & 0.067 & -0.72 & -0.46 & 0.126 & 0.502 & 44.60 & 36.83 & 51.40 \\
\hline & & Winter & $-0.65^{* *}$ & 0.067 & -0.78 & -0.52 & & & 48.00 & 40.74 & 54.37 \\
\hline & \multirow{2}{*}{ PE versus $\mathrm{CK}$} & Spring & $-0.39 * *$ & 0.076 & -0.54 & -0.24 & 0.149 & 0.458 & 32.49 & 21.59 & 41.87 \\
\hline & & Winter & $-0.31 * *$ & 0.075 & -0.46 & -0.17 & & & 26.90 & 15.23 & 36.96 \\
\hline & \multirow[t]{2}{*}{ PA versus CK } & Spring & $-0.72 * *$ & 0.056 & -0.83 & -0.61 & 0.216 & 0.819 & 51.26 & 45.59 & 56.35 \\
\hline & & Winter & $-0.74 * *$ & 0.052 & -0.84 & -0.63 & & & 52.11 & 46.94 & 56.79 \\
\hline & \multirow[t]{2}{*}{ PL versus CK } & Spring & $-0.58 * *$ & 0.064 & -0.71 & -0.45 & 0.121 & 0.279 & 44.02 & 36.51 & 50.64 \\
\hline & & Winter & $-0.48^{* *}$ & 0.062 & -0.60 & -0.36 & & & 38.36 & 30.45 & 45.37 \\
\hline \multirow[t]{12}{*}{ DON } & \multirow[t]{2}{*}{$\mathrm{CE}$ versus $\mathrm{CK}$} & Spring & $-0.27 * *$ & 0.057 & -0.39 & -0.16 & 0.036 & 0.409 & 23.95 & 15.00 & 31.95 \\
\hline & & Winter & $-0.21 * *$ & 0.048 & -0.31 & -0.12 & & & 19.16 & 11.25 & 26.35 \\
\hline & \multirow[t]{2}{*}{$\mathrm{CA}$ versus $\mathrm{CK}$} & Spring & $-0.67 * *$ & 0.056 & -0.78 & -0.56 & 0.120 & 0.012 & 48.69 & 42.68 & 54.07 \\
\hline & & Winter & $-0.49 * *$ & 0.043 & -0.57 & -0.40 & & & 38.61 & 33.17 & 43.61 \\
\hline & \multirow[t]{2}{*}{ CL versus $\mathrm{CK}$} & Spring & $-0.72 * *$ & 0.071 & -0.86 & -0.58 & 0.125 & 0.040 & 51.37 & 44.13 & 57.67 \\
\hline & & Winter & $-0.54 * *$ & 0.056 & -0.65 & -0.43 & & & 41.47 & 34.65 & 47.57 \\
\hline & \multirow{2}{*}{$\mathrm{PE}$ versus $\mathrm{CK}$} & Spring & $-0.34 * *$ & 0.057 & -0.46 & -0.23 & 0.026 & 0.298 & 29.13 & 20.74 & 36.64 \\
\hline & & Winter & $-0.27 * *$ & 0.047 & -0.36 & -0.17 & & & 23.44 & 15.96 & 30.25 \\
\hline & \multirow[t]{2}{*}{ PA versus $\mathrm{CK}$} & Spring & $-0.59 * *$ & 0.051 & -0.69 & -0.49 & 0.091 & 0.005 & 44.67 & 38.83 & 49.96 \\
\hline & & Winter & $-0.41 * *$ & 0.038 & -0.49 & -0.34 & & & 33.87 & 28.79 & 38.59 \\
\hline & \multirow[t]{2}{*}{ PL versus $C K$} & Spring & $-0.63 * *$ & 0.062 & -0.76 & -0.51 & 0.081 & 0.001 & 46.95 & 40.08 & 53.03 \\
\hline & & Winter & $-0.38 * *$ & 0.049 & -0.47 & -0.28 & & & 31.35 & 24.48 & 37.59 \\
\hline
\end{tabular}

${ }^{\mathrm{a}} \mathrm{IND}=$ Fusarium head blight index (mean percentage of diseased spikelets per spike); and DON = deoxynivalenol content of harvested grain.

${ }^{\mathrm{b}}$ Nontreated check (CK), metconazole applied before (CE), at (CA), or after (CL) 50\% early anthesis (Feekes 10.5.1), and prothioconazole + tebuconazole applied before (PE), at (PA), or after (PL) early anthesis.

${ }^{\mathrm{c}}$ Data obtained from winter wheat and spring wheat studies.

d $\bar{L}=$ mean log of the response ratio between pairs of treatments means; se $(\bar{L})=$ standard error of $\bar{L} ; C I_{L}$ and $C I_{U}=$ lower and upper limits of the $95 \%$ confidence interval around $\bar{L}$, respectively; $\hat{\sigma}^{2}=$ between-study variance; $P=$ significance level for wheat type; and $* *=$ statistical significance of $\bar{L}(P<0.001)$.

e $\bar{C}=$ mean percent control estimated as $\bar{C}=[1-\exp (\bar{L})] \times 100$; and $C I_{L}$ and $C I_{U}=$ lower and upper limits of the $95 \%$ confidence interval around $\bar{C}$, respectively. 
controls for treatments applied at anthesis in both wheat types were within the range of values reported previously by Paul et al. (2008) from a meta-analysis of UFT data collected prior to 2006 (a subset of that data was also used in this study). However, there were noticeable differences for comparisons of mean percent control values between wheat types based on estimates from the current study (from the analysis of a larger dataset that include trials conducted between 2006 and 2013) and those reported in Paul et al. (2008) for the smaller, older dataset. For instance, Paul et al. (2008), estimated the efficacy for anthesis application of prothioconazole + tebuconazole and metconazole against IND and reported it was significantly higher (approximately 13 and 20\%, respectively) for spring wheat than winter wheat. In contrast, comparable levels of efficacy were estimated in the current study for the two wheat types: $53 \%$ in spring wheat versus $52 \%$ in winter for metconazole and $51 \%$ spring wheat versus $52 \%$ in winter wheat for prothioconazole + tebuconazole.

Paul et al. (2008) hypothesized that an initial difference in cultivar resistance between spring and winter wheat trials was likely one of the primary reasons for the differences in fungicide efficacy they observed between trials from the two wheat types. We use a similar argument to explain the lack of a significant wheat type effect on the efficacy of the treatments evaluated in the current investigation against IND. Although cultivars categorized as susceptible were planted in all trials, susceptible spring wheat cultivars were relatively less susceptible than susceptible winter wheat cultivars prior to 2006, the dataset used in Paul et al. (2008). Since that initial quantitative synthesis of data from the first 8 years of UFTs (1998 to 2005), twice as many new UFTs were conducted, most of which were from soft red winter wheat growing regions (Bradley, personal communication).
During that same period, considerable progress was made developing SRWW cultivars with FHB resistance (Paul, personal communication), which led to old susceptible and resistant standards being replaced. For instance, in Ohio, the highly susceptible SRWW cultivar Elkart was replaced by the much less susceptible Hopewell in the UFTs; relative to Elkart and similar cultivars, Hopewell used to be considered moderately susceptible. Such a change resulted in the dataset used in this study being composed of a higher proportion of winter wheat trials with cultivars that are relatively less susceptible than those used in the first set of UFTs analyzed in Paul et al. (2008). Because fungicide efficacy against IND has been shown to be greater for moderately resistant and moderately susceptible cultivars than for susceptible cultivars (Willyerd et al. 2012), we hypothesize that narrowing the gap in terms of relative susceptibility between winter and spring cultivars in the UFT contributed to comparable fungicide efficacy between the two wheat types.

However, contrary to what was observed for IND, wheat type had a significant effect on the efficacy of anthesis and postanthesis applications against DON, for prothioconazole + tebuconazole or metconazole. Percent DON reduction relative to the nontreated check was 10 to $16 \%$ higher with spring wheat than with winter wheat. This is consistent with the results from Paul et al. $(2007,2008)$. DON is a complex trait that is not only influenced by cultivar resistance reaction and fungicide treatment effect but also by several other factors not controlled by, or beyond the control of, the investigators. DON levels in the grain often change after treatment application in response to weather conditions and late-season infections, even if the level of visual symptoms remains relatively unchanged (Cowger et al. 2009; Culler et al. 2007; Del Ponte et al. 2007; Hart et al.

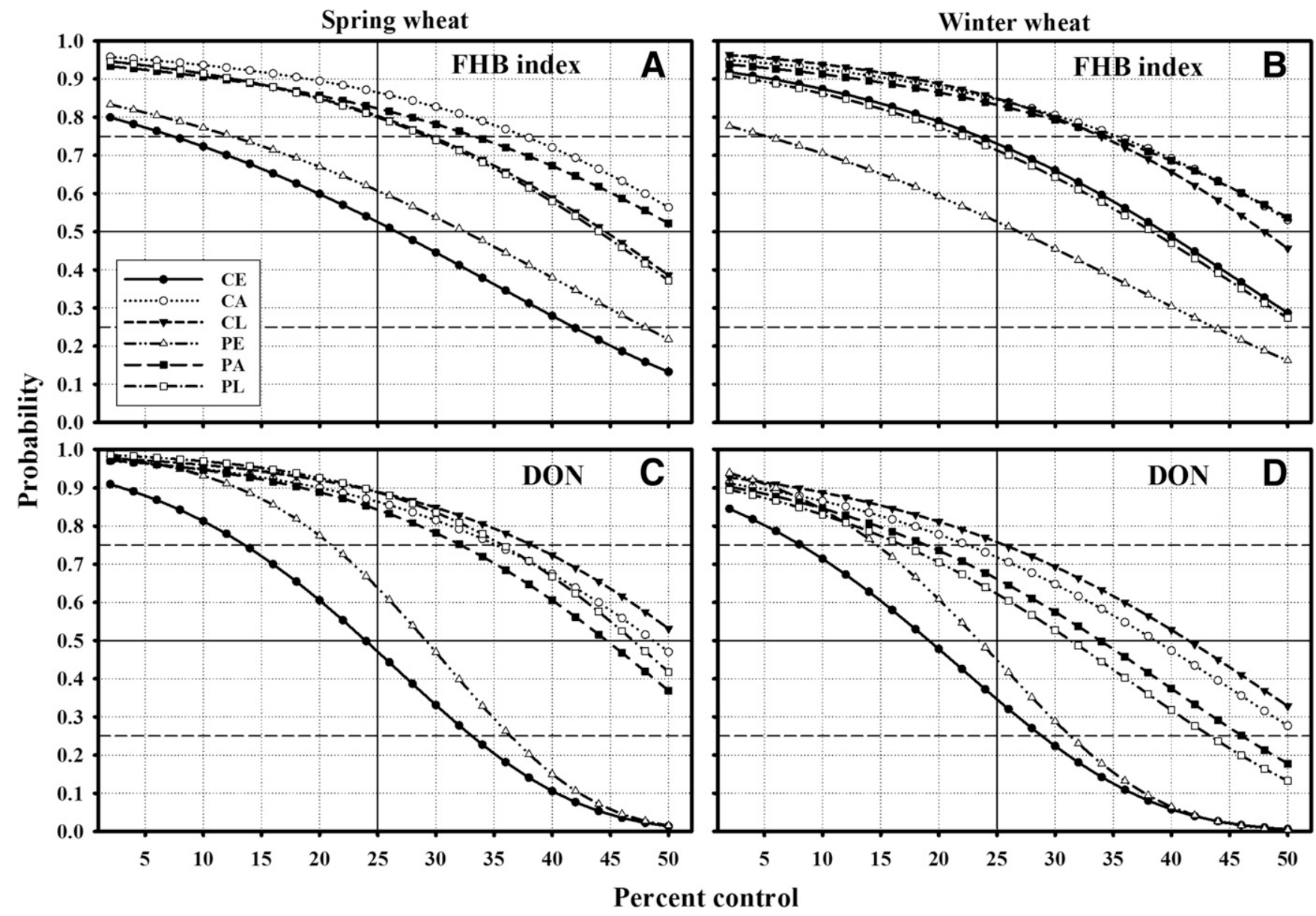

Fig. 3. Estimated probabilities of observing percent controls ranging from at least $2 \%$ to at least $50 \%$ for Fusarium head blight (FHB) index (A and B) and deoxynivalenol (DON) contamination ( $C$ and $\mathbf{D}$ ) of harvested grain relative to a nontreated check following the application of different fungicide treatments to FHB-affected plots in a new randomly selected spring or winter wheat trial. Treatments consisted of prothioconazole + tebuconazole applied before (PE), at (PA), or after (PL) $50 \%$ early anthesis (Feekes 10.5.1) and metconazole before $(\mathrm{CE})$, at $(\mathrm{CA})$, or after $(\mathrm{CL})$ early anthesis. Probability values were calculated using the mean log response ratios and their between-study variances in Table 4 estimated through network meta-analysis. Horizontal reference lines show probabilities of $0.25,0.50$, and 0.75 , and vertical reference lines show $25 \%$ control. 
1984). Environmental conditions were likely responsible, at least in part, for differences in the efficacy of anthesis and postanthesis treatments against DON between spring and winter wheat trials. For instance, owing to cooler, wetter weather conditions, the anthesis window and grain-fill periods are usually longer in winter wheat than in spring wheat. This could have resulted in late infections, grain colonization, and accompanying DON accumulation starting several days after the application of fungicides and thus when the fungicides were less effective. These processes may have all occurred without corresponding increases in visual symptom expression (Cowger and Arrellano 2010; Lacey et al. 1999) and were likely less frequent in spring wheat growing regions owing to much shorter anthesis and early grain-fill periods and hotter, dryer postanthesis weather conditions. Compressed anthesis and early grain-fill windows in spring wheat likely result in more synchronized crop development and, consequently, in more spikes being treated at the desired growth stage in spring wheat compared with winter wheat trials.

Based on a summary of 20 years (1995 to 2014) of weather data from spring and winter wheat growing regions, mean daily temperature, averaged over the last 15 days before anthesis, was $3.5^{\circ} \mathrm{C}$ warmer in spring wheat trials than in winter wheat trials, whereas mean relative humidity during the same preanthesis window was almost identical, 69.2 and 69.1 for spring and winter wheat trials, respectively. These data were collected from weather stations or downloaded from data archives for periods and locations congruent with the UFTs (see Shah et al. [2013] for details). Although these empirical observations may suggest an association between local conditions and fungicide efficacy, the effect of temperature on the duration of anthesis and grain-fill and, consequently, the length of the infection window, is unlikely to be the only reason for the observed differences in percent control of DON between spring and winter wheat regions. Therefore, from a practical standpoint, temperature alone is unlikely to be predictive of fungicide efficacy against DON. Further research would be needed to formally evaluate associations between pre- and postanthesis temperatures and the efficacy of prothioconazole + tebuconazole or metconazole, as influenced by other factors such as cultivar maturity and production practices that are known to affect wheat growth and development, as well as weather-, host-, and pathogen-related factors that affect $F$. graminearum infection, FHB development, and DON accumulation.

All fungicide treatments resulted in a significant increase in mean grain yield relative to the nontreated check. The magnitude of the response was similar among metconazole treatments but was higher for the anthesis application compared with pre- or postanthesis applications for prothioconazole + tebuconazole. The superior efficacy of the anthesis and postanthesis metconazole treatments over the preanthesis treatments against FHB visual symptom development did not translate into significantly higher yield gains. This is not uncommon for fungicide trials, because yield response is not only a function of the diseases being targeted. In fact, for prothioconazole + tebuconazole, the yield response was likely due not only to superior FHB control but also to the control of other diseases during the critical grain-fill period, because this fungicide is known to be effective against a number of foliar diseases (Salgado et al. 2017; Willyerd et al. 2015). Keeping the spikes and upper leaves disease-free, or at a reduced disease level, is important for grain yield and quality (Ruske et al. 2003; Simpson 1968). Although yield is important, grain quality in terms of DON reduction and test weight increase is often just as or even more important when managing FHB. Results from economic analyses of data from FHB management trials showed that even if there is a yield increase in response to a given management program, if that program does not reduce DON below, and increase test weight above, critical grain marketing thresholds, economic losses may still occur as a result of price discounts (Cowger et al. 2016; Salgado et al. 2014). In this study, test weight increases were associated with efficacy against IND, because the four treatments (PA, PL, CA, and CL) that resulted in the highest mean percent control of IND also resulted in the highest mean increases in test weight. This is likely because there is often a significant negative relationship between IND and test weight (Salgado et al. 2015), because FHB development is commonly associated with damage to kernels (shriveled and lightweight), which directly affects test weight (a measure of grain weight for unit volume).

In this study we not only estimated the overall efficacy of prothioconazole + tebuconazole and metconazole, two of the most effective and widely used fungicides for FHB management, we also generated information useful for making future application decisions when choosing between the two products and among the three tested application times. We present evidence confirming the importance of anthesis as an appropriate target growth stage for applying fungicides to manage FHB. Because both prothioconazole + tebuconazole and metconazole are rainfast within the first hour after treatment application (Andersen et al. 2014; Mills et al. 2017), producers should strive to apply treatments at anthesis even if rain is in the forecast. However, if adverse field conditions or other factors prevent applications from being made at anthesis, the next best option according to our results would be to apply treatments within a 5- to 7-day window after rather than in the 5 to 7 days before anthesis. Missing the anthesis window therefore should not be a justification for not treating fields when the risk of FHB is high. Based on estimated probabilities of percent control in future studies (Fig. 3), producers are more likely to see the highest levels of FHB and DON control if they choose to apply treatments at or shortly after anthesis than at heading, which is a few days before anthesis. Late applications were just as effective as anthesis applications at reducing DON, and if a late application has to be made, metconazole would be a better choice of fungicide. This was the case for both wheat types, although fungicide efficacy for DON was higher with spring than with winter wheat.

\section{Acknowledgments}

This is a cooperative project with the U.S. Wheat \& Barley Scab Initiative (agreements \# 59-0206-4-018 [The Ohio State University], 59-0206-4-006 [Cornell University], 59-0206-4-042 [Purdue University], and 59-0206-4-016 [The University of Minnesota]). Any opinions, findings, conclusions, or recommendations expressed in this publication are those of the authors and do not necessarily reflect the view of the U.S. Department of Agriculture. Special thanks to W. Bardall, M. Wallhead, and the Snyder farm crew for assisting with the establishment and maintenance of plots in Wooster, $\mathrm{OH}$

\section{Literature Cited}

Andersen, K. F., Morris, L., Derksen, R. C., Madden, L. V., and Paul, P. A. 2014 Rainfastness of prothioconazole + tebuconazole for Fusarium head blight and deoxynivalenol management in soft red winter wheat. Plant Dis. 98:1398-1406.

Blandino, M., Haidukowski, M., Pascale, M., Plizzari, L., Scudellari, D., and Reyneri, A. 2012. Integrated strategies for the control of Fusarium head blight and deoxynivalenol contamination in winter wheat. Field Crops Res. 133:139-149.

Boyacioglu, D., Hettiarachchy, N. S., and Stack, R. W. 1992. Effect of three systemic fungicides on deoxynivalenol (vomitoxin) production by Fusarium graminearum in wheat. Can. J. Plant Sci. 72:93-101.

Bradley, C. A., Adee, E. A., Ebelhar, S. A., Dill-Macky, R., Wiersma, J. J., Grybauskas, A. P., Kirk, W. W., McMullen, M. P., Halley, S., Milus, E. A., Osborne, L. E., Ruden, K. R., and Young, B. G. 2010. Multi-state uniform fungicide evaluations for control of Fusarium head blight and associated mycotoxins. Page 74 in: Proc. 2010 National Fusarium Head Blight Forum. S. Canty, A. Clark, A. Anderson-Scully, D. Ellis, and D. Van Sanford, eds. Milwaukee, WI.

Bradley, C. A., Adee, E. A., Ebelhar, S. A., Grybauskas, A. P., Hollingsworth C. R., Kirk, W. W., McMullen, M. P., Milus, E. A., Osborne, L. E., Ruden, K. R., and Young, B. G. 2009. Application timings of Caramba and Prosaro foliar fungicides for management of FHB and DON. Page 34 in: Proc. 2009 National Fusarium Head Blight Forum. S. Canty, A. Clark, J. Mundell, E. Walton, D. Ellis, and D. Van Sanford, eds. Orlando, FL.

Buerstmayr, H., Blöch, D., Hasitschka, S., Buerstmayr, M., Maloku, I., Schweiger, W., Lemmens, L., and Steiner, B. 2013. Association between anther-retention and Fusarium head blight susceptibility in wheat. 64. Jahrestagung der Vereinigung der Pflanzenzüchter und Saatgutkaufleute Österreichs, November 25-26, Raumberg-Gumpenstein, Austria.

Chen, Y., Zhang, A.-F., Gao, T.-C., Zhang, Y., Wang, W.-X., Ding, K.-J., Chen, L., Sun, Z., Fang, X.-Z., and Zhou, M.-G. 2012. Integrated use of pyraclostrobin and epoxiconazole for the control of Fusarium head blight of wheat in Anhui Province of China. Plant Dis. 96:1495-1500.

Cowger, C., and Arrellano, C. 2010. Plump kernels with high deoxynivalenol linked to late Gibberella zeae infection and marginal disease conditions in winter wheat. Phytopathology 100:719-728. 
Cowger, C., Patton-Ozkurt, J., Brown-Guedira, G., and Perugini, L. 2009. Postanthesis moisture increased Fusarium head blight and deoxynivalenol levels in North Carolina winter wheat field experiment. Phytopathology 99:320-327.

Cowger, C., Weisz, R., Arellano, C., and Murphy, P. 2016. Profitability of integrated management of Fusarium head blight in North Carolina winter wheat. Phytopathology 106:814-823.

Culler, M. D., Miller-Garvin, J. E., and Dill-Macky, R. 2007. Effect of extended irrigation and host resistance on deoxynivalenol accumulation in Fusariuminfected wheat. Plant Dis. 91:1464-1472.

D’Angelo, D. L., Bradley, C. A., Ames, K. A., Willyerd, K. T., Madden, L. V., and Paul, P. A. 2014. Efficacy of fungicide applications during and after anthesis against Fusarium head blight and deoxynivalenol in soft red winter wheat. Plant Dis. 98:1387-1397.

Del Ponte, E. M., Fernandes, J. M. C., and Bergstrom, G. C. 2007. Influence of growth stage on Fusarium head blight and deoxynivalenol production in wheat. J. Phytopathol. 155:577-581.

Edwards, S. G., and Godley, N. P. 2010. Reduction of Fusarium head blight and deoxynivalenol in wheat with early fungicide applications of prothioconazole. Food Addit. Contam. Part A 27:629-635.

Graham, S., and Browne, R. A. 2009. Anther extrusion and Fusarium head blight resistance in European wheat. J. Phytopathol. 157:580-582.

Hart, L. P., Pestka, J. J., and Liu, M. T. 1984. Effect of kernel development and wet periods on production of deoxynivalenol in wheat infected with Gibberella zeae. Phytopathology 74:1415-1418.

Hershman, D. E., and Milus, E. A. 2002. Analysis of the 2002 uniform wheat fungicide and biocontrol trials across locations. Pages 82-87 in: Proc. Natl. Fusarium Head Blight Forum. Michigan State University, East Lansing.

Holb, I. J. and Schnabel, G. 2007. Differential effect of triazoles on mycelial growth and disease measurements of Monilinia fructicola isolates with reduced sensitivity to DMI fungicides. Crop Prot. 26:753-759.

Hunsche, M., Bringe, K., Schmitz-Eiberger, M., and Noga, G. 2006. Leaf surface characteristics of apple seedlings, bean seedlings and kohlrabi plants and their impact on the retention and rainfastness of mancozeb. Pest Manag. Sci. 62: $839-847$.

Ivic, D. 2010. Curative and eradicative effects of fungicides. Pages 3-22 in: Fungicides. O. Carisse, ed. InTech, Rijeka, Croatia.

Kubo, K., Fujita, M., Kawada, N., Nakajima, T., Nakamura, K., Maejima, H., Ushiyama, T., Hatta, K., and Matsunaka, H. 2013. Minor differences in anther extrusion affect resistance to Fusarium head blight in wheat. J. Phytopathol. 161:308-314.

Kubo, K., Kawada, N., Fujita, M., Hatta, K., Oda, S., and Nakajima, T. 2010. Effect of cleistogamy on Fusarium head blight resistance in wheat. Breed. Sci. 60:405-411.

Lacey, J., Bateman, G. L., and Mirocha, C. J. 1999. Effects of infection time and moisture on development of ear blight and deoxynivalenol production by Fusarium spp. in wheat. Ann. Appl. Biol. 134:277-283.

Large, E. C. 1954. Growth stages in cereals. Plant Pathol. 3:128-129.

Littell, R. C., Milliken, G. A., Stroup, W. W., Wolfinger, R. D., and Schabenberger, O. 2006. SAS System for Mixed Models. SAS Institute, Cary, NC

Lori, G. A., Sisterna, S. J., Rizzo, I., and Chidichimo, H. 2009. Fusarium head blight in wheat: Impact of tillage and other agronomic practices under natural infection. Crop Prot. 28:495-502.

Lu, Q., Lillemo, M., Skinnes, H., He, X., Shi, J., Ji, F., Dong, Y., and Bjørnstad, A. 2013. Anther extrusion and plant height are associated with type I resistance to Fusarium head blight in bread wheat line 'Shanghai-3/Catbird'. Theor. Appl. Genet. 126:317-334.

Madden, L. V., and Paul, P. A. 2009. Assessing heterogeneity in the relationship between wheat yield and Fusarium head blight intensity using randomcoefficient mixed models. Phytopathology 99:850-860.

Madden, L. V., and Paul, P. A. 2011. Meta-analysis for evidence synthesis in plant pathology: An overview. Phytopathology 101:16-30.

Madden, L. V., Piepho, H.-P., and Paul, P. A. 2016. Statistical models and methods for network meta-analysis. Phytopathology 106:792-806.

Mauler-Machnik, A., and Suty, A. 1997. New findings on the epidemiology, importance and control of Fusarium ear blight on wheat. Cereal Res. Commun. 255:705-709.

McMullen, M., Bergstrom, G., De Wolf, E., Dill-Macky, R., Hershman, D., Shaner, G., and Van Sanford, D. 2012. A unified effort to fight an enemy of wheat and barley: Fusarium head blight. Plant Dis. 96:1712-1728.

McMullen, M., Halley, S., Schatz, B., Meyer, S., Jordahl, J., and Ransom, J. 2008. Integrated strategies for Fusarium head blight management in the United States. Cereal Res. Commun. 36 (Suppl. 6):563-568.

McMullen, M., Milus, G., and Prom, L. 1999. 1999 Uniform fungicide trials to identify products effective against Fusarium head blight in wheat. Pages 64-68 in: Proc. 1999 Natl. Fusarium Head Blight Forum. Michigan State University, East Lansing.

Mills, K. B., Salgado, J. D., Madden, L. V., and Paul, P. A. 2017. The spray before the storm: Assessing the rainfastness of Caramba for control of Fusarium head blight. Page 16 in: Proc. 2017 National Fusarium Head Blight Forum. S. Canty, B. Wiermer, and D. Van Sanford, eds. Milwaukee, WI.

Paul, P. A., Bradley, C. A., Madden, L. V., Dalla Lana, F., Bergstrom, G. C., DillMacky, R., Esker, P., Wise, K. A., McMullen, M. P., Grybauskas, A., Kirk, W.,
Milus, E. A., and Ruden, K. In press. Meta-analysis of the effects of QoI and DMI fungicide combinations on Fusarium head blight and deoxynivalenol in wheat. Plant Dis.

Paul, P. A., Lipps, P. E., Hershman, D. E., McMullen, M. P., Draper, M. A., and Madden, L. V. 2007. A quantitative review of tebuconazole effect on Fusarium head blight and deoxynivalenol content in wheat. Phytopathology 97:211-220.

Paul, P. A., Lipps, P. E., Hershman, D. E., McMullen, M. P., Draper, M. A., and Madden, L. V. 2008. Efficacy of triazole-based fungicides for Fusarium head blight and deoxynivalenol control in wheat: A multivariate meta-analysis. Phytopathology 98:999-1011.

Paul, P. A., Lipps, P. E., and Madden, L. V. 2005. Relationship between visual estimates of Fusarium head blight intensity and deoxynivalenol accumulation in harvested wheat grain: A meta-analysis. Phytopathology 95:1225-1236.

Paul, P. A., Lipps, P. E., and Madden, L. V. 2006. Meta-analysis of regression coefficients for the relationship between Fusarium head blight and deoxynivalenol content of wheat. Phytopathology 96:951-961.

Paul, P. A., McMullen, M. P., Hershman, D. E., and Madden, L. V. 2010. Metaanalysis of the effects of triazole-based fungicides on wheat yield and test weight as influenced by Fusarium head blight intensity. Phytopathology 100: 160-171.

Ruske, R. E., Gooding, M. J., and Jones, S. A. 2003. The effects of adding picoxystrobin, azoxystrobin and nitrogen to a triazole programme on disease control, flag leaf senescence, yield and grain quality of winter wheat. Crop Prot. 22:975-987.

Salgado, J. D., Lindsey, L., and Paul, P. A. 2017. Effects of row spacing and nitrogen rate on wheat grain yield and profitability as influenced by diseases. Plant Dis. 101:1998-2011.

Salgado, J. D., Madden, L. V., and Paul, P. A. 2014. Efficacy and economics of integrating in-field and harvesting strategies to manage Fusarium head blight of wheat. Plant Dis. 98:1407-1421.

Salgado, J. D., Madden, L. V., and Paul, P. A. 2015. Quantifying the effects of Fusarium head blight on grain yield and test weight in soft red winter wheat Phytopathology 105:295-306.

Schnabel, G., Bryson, P. K., Bridges, W. C., and Brannen, P. M. 2004. Reduced sensitivity in Monilinia fructicola to propiconazole in Georgia and implications for disease management. Plant Dis. 88:1000-1004.

Schöfl, U. A., and Zinkernagel, V. 1997. A test method based on microscopic assessments to determine curative and protectant fungicide properties against Septoria tritici. Plant Pathol. 46:545-556.

Shah, D. A., Molineros, J. E., Paul, P. A., Willyerd, K. T., Madden, L. V., and De Wolf, E. D. 2013. Predicting Fusarium head blight epidemics with weatherdriven pre- and post-anthesis logistic regression models. Phytopathology 103 906-919.

Simpson, G. M. 1968. Association between grain yield per plant and photosynthetic area above the flag leaf node in wheat. Can. J. Plant Sci. 48:253-260.

Stack, R. W., and McMullen, M. P. 1998. A visual scale to estimate severity of Fusarium head blight in wheat. Online publication PP-1095. North Dakota State University Extension Service, Fargo.

Tateishi, H., Miyake, T., Mori, M., Sakuma, Y., and Saishoji, T. 2014. Effect of application timing of metconazole on Fusarium head blight development and mycotoxin contamination in wheat and barley. J. Pestic. Sci. 39:1-6.

van Houwelingen, H. C., Arends, L. R., and Stijnen, T. 2002. Advanced methods in meta-analysis: Multivariate approach and meta-regression. Stat. Med. 21: 589-624.

Vicent, A., Armengol, J., and Garcia-Jimenez, J. 2007. Rain fastness and persistence of fungicides for control of Alternaria brown spot of citrus. Plant Dis. 91:393-399.

Wang, M.-Y., Baenziger, P. S., El-Basyoni, I. S., and Wegulo, S. N. 2015. Comparison of Fusarium head blight resistance in cytoplasmic male sterile, maintainer and restorer lines in winter wheat. Cereal Res. Commun. 43:374-383.

Wegulo, S. N., Bockus, W. W., Nopsa, J. H., De Wolf, E. D., Eskridge, K. M., Peiris, K. H. S., and Dowell, F. E. 2011. Effects of integrating cultivar resistance and fungicide application on Fusarium head blight and deoxynivalenol in winter wheat. Plant Dis. 95:554-560.

Wiersma, J. J., and Motteberg, C. D. 2005. Evaluation of five fungicide application timings for control of leaf-spot diseases and Fusarium head blight in hard red spring wheat. Can. J. Plant Pathol. 27:25-37.

Willyerd, K. T., Bradley, C. A., Chapara, V., Conley, S. P., Esker, P. D., Madden, L. V., Wise, K. A., and Paul, P. A. 2015. Revisiting fungicide-based management guidelines for leaf blotch diseases in soft red winter wheat. Plant Dis. 99:1434-1444.

Willyerd, K. T., Li, C., Madden, L. V., Bradley, C. A., Bergstrom, G. C., Sweets, L. E., McMullen, M., Ransom, J. K., Grybauskas, A., Osborne, L., Wegulo, S N., Hershman, D. E., Wise, K., Bockus, W. W., Groth, D., Dill-Macky, R., Milus, E., Esker, P. D., Waxman, K. D., Adee, E. A., Ebelhar, S. E., Young, B. G., and Paul, P. A. 2012. Efficacy and stability of integrating fungicide and cultivar resistance to manage Fusarium head blight and deoxynivalenol in wheat. Plant Dis. 96:957-967.

Yoshida, M., Nakajima, T., Tomimura, K., Suzuki, F., Arai, M., and Miyasaka, A 2012. Effect of the timing of fungicide application on Fusarium head blight and mycotoxin accumulation in wheat. Plant Dis. 96:845-851.

Zadoks, J. C., Chang, T. T., and Konzak, C. F. 1974. A decimal code for the growth stages of cereals. Weed Res. 14:415-421. 